\title{
Embedding WBSM into Curriculum for Improving Graduate Employability
}

\author{
Aarthi Nagappan, Rajesh Subramanian \\ Botho College, Botswana
}

\begin{abstract}
The curriculum being taught at universities though valuable and imparts knowledge, fails in preparing the graduates in the industry expected style [1]. Universities are known for their core competencies but somehow lack in training students on the workable front. So it is important for the HEIs to recognize the growing employability concern and introduce measures (e.g.) Modifications to the existing curriculum aiming on developing student's wider attributes and employability skills alongside their subject knowledge and academic skills. Good curriculum design should help learner construct understanding of not only subject matter but also develop skillful practices that could enable them to find appropriate jobs. Employability audits are becoming prominent and test how and where employability requirements are incorporated into existing curricula and where there might be gaps needing attention. Authors in this paper underwent a thorough analysis of their existing curriculum and have developed a work based skills module (WBSM) for incorporation into the curriculum. This suggested module will cater to training the student on employability skills (ie) Communication, Team building, Time and stress management, etc... Authors strongly believe in the effective re-design of curriculum as a powerful tool to build employability traits and hence confidence in future graduates to face the competitive job market. The proposed recommendations will have greater influence on preparing young graduates for their futures through education platform. Hopefully with this new curriculum changes are bound to happen whereby there would no longer be a hassle in the job market for graduates to find jobs.
\end{abstract}

\section{Introduction}

"The widening gap between academia and industry in relation to graduate output and industry's demand has become a perennial problem" [2]. The count of graduates coming out of the institutions is ever increasing with either shortage of jobs for all of them or not enough trained graduates for the existing jobs as can been seen "... a severe skills shortage, employability is attracting increasing attention from industry, students and government"[3]. The industries that recruit these graduates complain about the quality and standards of these job seekers and express the need for an in house training to be given to selected candidates before putting them to job. The additional reviews from the literature also confirms skills mismatch, "...there is a serious mismatch of skills training and education supply with labor market demands" [4] leading to unemployment and this growing unemployment situation is demanding immediate attention and action on the part of Universities.

Some of the factors informing this are considered and necessitates higher education institutions to redesign curriculum in incorporating work based skills module. This is gaining momentum and is the core discussion of this paper.

In a general sense, 'employability' relates to a person's ability to gain employment [3]. Universities focus on the technical skills or hard skills and need to start focusing on developing other soft skills like communication; teamwork; independent thinking; problem solving, etc...in addition to the subject knowledge and academic skills needed for a good job. "...poor in communication and other soft skills. So the organizations are compelled to spend considerable amount of time and money in mentoring these fresher's for promising productivity [5]. So why not design a curriculum that will help learners construct understandings of the subject matter as well as build work related skills while at study? This curriculum redesign will increases the chances for the employment and for the employer savings on in house training efforts and resources.

One size does not fit all institutions, as far as employability is concerned. Contexts, student recruitment patterns, envisaged labor markets and traditions are four variables that influence the embedding of employability in curricula [6].

"The establishment of clear mechanisms by which students can develop their abilities to use and deploy a wide range of skills and opportunities to enhance their own academic learning and enable them to become more employable"[7]. The consideration of introducing work based skills in curriculum will definitely contribute to the improved employability skills in the student to meet the demands of the job market. Thus, this new work based skills module should hopefully see most if not all graduates are fully equipped for the employment in the long run. 


\section{Methodology}

This curriculum redesign process began with a careful analysis of the existing curriculum to see where and how much the existing curriculum contributes to preparing students on employability front. Varied tools are available in the market to carry out the employability audit whose outcome is to reveal strengths and weaknesses in current curriculum and help in identifying gaps that needs to be addressed. Authors used the following approach detailed as steps below to check the curriculum for fostering employability traits in graduates.

1. Find out what are we doing in current curriculum

2. Map the skills that are developed as part of existing curriculum

3. Are we really helping students to develop these skills?

4. Prioritize the skills based on importance to work.

5. Check if you are doing enough in building those skills through curriculum

6. Identify gaps needing attention

7. Find solutions to address the gap

8. Find ways to embed these skills as part of new/revised curriculum to support future graduates

This curriculum analysis revealed gaps and suggested need for changes to be introduced to existing curriculum towards fostering employability skills in future graduates. The modifications to the existing curriculum was based on inputs from industry experts to understand the skill set expected of employable graduates and guidance from experienced designers with expertise to suitably redesign curriculum to meet the demands of growing job market. This triggered the incorporation of the WBSM in to the curriculum. There were a number of factors that needed to be considered during redesign as the module was expected to build necessary employability skills in students benefiting student community and society at large on the employability grounds.

Embedding of WBSM in to the curriculum is based on a three step iterative process as discussed in Figure 1.

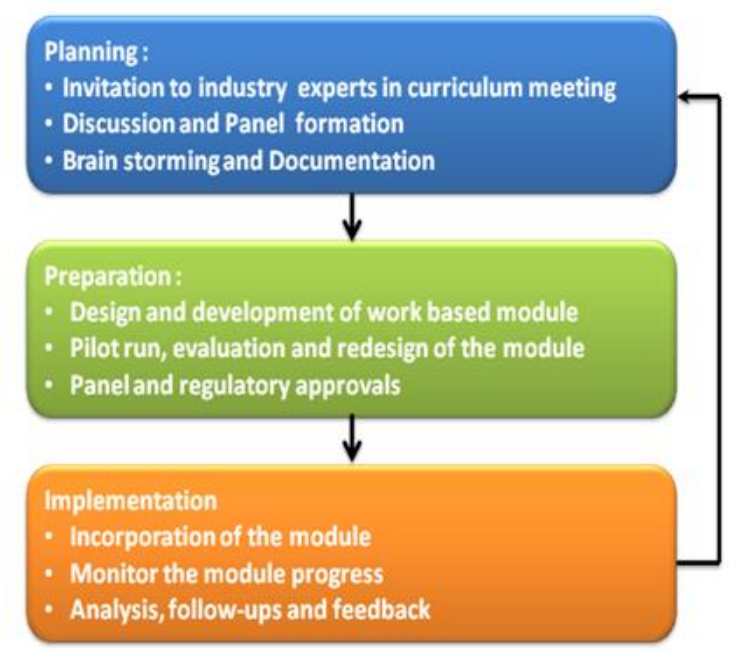

Figure 1. Steps involved in design of WBSM

The authors in this paper have discussed majorly on steps 1,2 and ran a pilot study to evaluate the design of the newly designed module.

The actual implementation as part of curriculum is yet to follow upon approval from the concerned authorities. However driven by the need for training a batch of students who are about to go on their second internship, authors with the support from management and other colleagues ran support sessions for these students aimed at developing relevant skills as identified to be lacking from the SWOT analysis and feedback submitted by these students to their tutors after their first internship. Participation of undergraduates in the training process and obtaining the feedback from the stakeholders are more important for understanding the trainee undergraduates ${ }^{6}$ future skills development areas [8].

The success and the usefulness of the support sessions are discussed under subsection 2.3.3 and affirms hope on the recommendations made by the authors in redesigning curriculum using WBSM for future graduates to find jobs in the competitive job market. The following sections will explain the 3 steps leading to the redesigned curriculum.

\subsection{Planning}

The quality design of WBSM heavily relies on inputs from the industry as they are the one who absorb the graduates [9]. Equally important would be the academicians in the design process, as they better understand the intricacies and complexities behind varied curriculums suggesting suitable modification as needed. 
These key people will be invited to take part in the pre design meeting where they will discuss on what soft skills are expected towards employment and how it can be incorporated into the existing curriculum. All of the brainstorming sessions were documented for future reference.

This initial meeting, paved way for the panel formation whereby the participants were free to make their decision to become part of the panel. Henceforth this formed panel would contribute to the design and follow-up reviews of WBSM through their timely suggestions

\subsection{Preparation}

\subsubsection{Design and development of WBSM}

This new module is designed to bridge the gap between the industry and academia by preparing the skilled manpower for the job market. It was agreed by the panel during the brainstorming sessions that a student should have sufficient technical knowledge, soft skills and right attitude to get placed immediately after graduation. The said soft skills can be improved in our students through teaching WBSM to them comprising of the below mentioned skills: communication, team building, time and stress management, self awareness and motivation, problem solving skills, conflict management and leadership skills.

Looking at the module content and expected quality outcome it is advisable to spread the module across the programme tenure for better results. Assuming a four year degree programme the initial two years would lay the foundation for the programme studied alongside the development of other essential soft skills. The third and final year would help the students on specializing in selected technical areas and would expose them to the real world environment by getting them trained in the industry. This gives the student the opportunity to apply the acquired knowledge and soft skills in addition to the learning from the training. Real time exposure has already been catered in the existing curriculum through the design of internship module in the second, third years and final year projects requiring no further changes. Figure 2 depict the structure of the redesigned curriculum from existing curriculum for 4 years 8 semesters programme run at Botho College. However this could vary with curriculum for other programmes.

The technical subject titles (TS) in the existing curriculum are not shown in Figure 2 considering the fact that this redesigning of curriculum can be applied to varied faculties i.e., computing, law, accounting, medicine etc., each having its own curriculum structure.

The designing of the module descriptor will give an insight in to the module. The module descriptor comprises of the learning outcomes, course content, credit rating, delivery and assessment pattern.

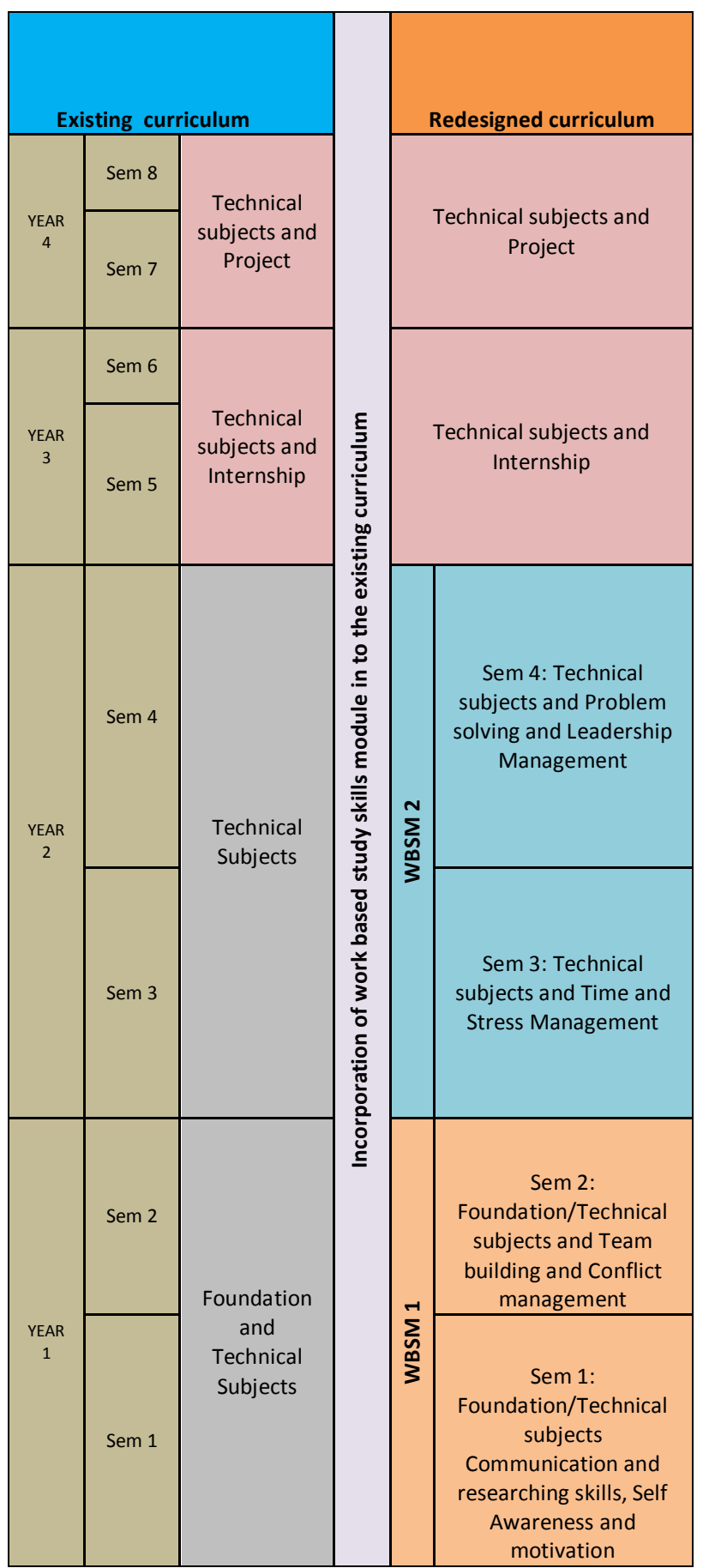

Figure 2. Structure of existing and redesigned curriculum 
2.2.2. Learning outcomes. At the end of this module the student will be able to:

- Demonstrate competence in applying the reading, writing, presentation and researching skills to appropriate situations.

- To create self awareness and introduce suitable personal changes for self development.

- To improve group dynamics for cooperative learning and development.

- To develop skills for efficient handling of time and managing stress.

- Demonstrate a theoretical and operational understanding of the problem; think critically to generate a viable solution of high standards.

- Develop and Demonstrate leadership traits

2.2.3. Course content. The WBSM is structured as two sub modules each spread across a year. Each year accommodates 2 semesters and semester-wise indicative content is discussed below:

Table 1. WBSM 1 content [First Year]

Semester 1:

Communication and Researching skills

Importance of effective communication, types and usage of appropriate communication styles: Reading, writing, oral, presentation. Information search and analysis skills etc.,

\section{Self awareness and motivation}

Key areas of awareness - learning style, cognitive styles, effective and efficient workings; personal values and ethics; decision-making capabilities; SWOT analysis, attitudinal and behavioral changes; self development

Semester 2

Team Building

Team vs Group, understanding group dynamics, Developing teams and teamwork;

Conflict management

Types of conflict, Issues leading to conflict, response styles, managing chaos, negotiating and resolving conflicts

Table 2. WBSM 2 content [Second year]
Semester 3

Time management

Importance of Time management, procrastination and its consequences, prioritizing, estimating and planning time

Stress management

Types of stress, causes of stress, stress reduction techniques, stress handling

Semester 4

Problem solving

Conceptual blocks, approaches to problem solving, critical thinking and creativity, effective decision making,

Leadership

Leader versus manager, leadership styles and theories, Leadership skills and effective management

2.2.4. Credit rating and delivery. Authors suggested on awarding 20 credits for a successful semester completion which is open for changes based on the institution and existing curriculum. These 20 credits equals to 200 hours (100 hours of teaching and learning and $100 \mathrm{hrs}$ of independent learning). However, this is also likely to vary based on the institution and its country of application. $100 \mathrm{hrs}$ of teaching and learning comprises of lecture sessions, seminars presentations, practical activities, role plays, tutorials, workshops etc. The delivery mode can be one of the above based on the concepts chosen for delivery.

2.2.5. Assessment. There would be two assessments for the entire module each spaced at the end of the year/sub module. Authors recommend portfolio assessment for the WBSM 1 and case study evaluation for WBSM 2. The reason being students need to be evaluated on the said learning outcomes.

The portfolio assessment would comprise of documenting and reflecting the activities carried out during WBSM 1 in addition to testing the students on writing and presentation skills. The case study evaluation is designed to give a comprehensive picture of the student's ability to work in group to understand, analyze and solve problems within the available time and stress levels. It will also look into the strategy adopted by the students to handle the problem, measuring them on their problem solving and leadership capabilities. 
2.2.6.Reviewers Feedback and Modification. Initial design of the module with entire WBSM content (WBSM 1 + WBSM 2) designed for delivery in a single semester was shared with a team of four reviewer's namely an industry expert, career advisor, a curriculum designer and tutor representative inviting suggestions towards improved module design.

The reviewer's had a varied opinion on where to fit this module in the existing curriculum. However when the discussions were turning in to a debate the curriculum designer put an end by suggesting a good idea of spreading the WBSM content across the years which was agreed by the other reviewers and authors.

This led the authors to carefully review their design again for incorporating the suggested changes. As a result the newly designed WBSM is broken into sub modules namely WBSM1 and 2 to be delivered across year 1 and 2 respectively. This spreading across 2 years/4 semesters would provide Sufficient time for qualitative delivery and development of said skills in the students.

Also, the career advisor pointed out the need for self awareness and motivation as the key towards self development and this thought was well appreciated by the authors and included as part of WBSM in the iterative redesign of the module.

2.2.6. Pilot run and feedback. The redesigned module after making changes based on reviewer's inputs was pilot run for a group of fresh tutors who were about to embark on teaching career. considering the available time it was not possible to cover the entire module content for these fresher's which left them with ideas and techniques on certain areas of the module content. However the verbal feedback from these tutors affirmed the usefulness of this module in preparing the graduates for the job market.

\subsection{Implementation}

Curriculum being a crucial component in imparting knowledge and relevant skills towards developing graduates for immediate employment, requires careful and through review which involves time for approvals to happen. Whilst the approval of this module will bring benefit to the fresh students who will come under this new curriculum, it disadvantages the current students who are left behind employer's expectations. This has driven the authors to come up with plans that would support the current students as well in developing their employability traits. Considering the limited time available prior to their second internship the scope of running the WBSM module was confined to certain key skills which needed immediate attention. Unlike
WBSM which is designed to be a credit rated module, the support sessions are not summative and are aimed at assisting the students on developing the required employability skills.

2.3.1.Incorporation of the module. As a part of their focus on enhancing employability Botho College, Botswana has developed an IGP internship programme. The curriculum for computing expects their graduates to undertake two mandatory internships to expose themselves to the industry requirements.

Since the WBSM module is currently under review for approval, it was not possible to include in the curriculum. However to benefit the current students who are about to go on their second internship, some of key skills listed in WBSM were taught to students in the form of support sessions. The course outline for support sessions was prepared based on the questionnaire feedback sought from the students who returned from their first internship, semi structured interviews with few internship supervisors and employers which revealed that there is a need for development on certain key employability skills. This instigated support sessions to be scheduled on those identified skills most of which have been covered as part of WBSM.

An attitude survey was conducted with 506 interns who returned from their first internship to gauge the benefits of the internship and learning. Out of 506 interns 433 participated in this survey, out of which 57 questionnaires were partially filled. And 16 interns did not manage to hand in the questionnaire. The fully completed and returned questionnaires were alone considered for interpretation and data analysis. The summarized findings are stated below,

In the attitude survey the questions were sought to understand the following:

- Usefulness of internship;

- Contribution of internship in developing employability skills;

- Skills needing improvement;

- Will support sessions be useful.

The findings from the survey are discussed below

\section{Usefulness of Internship}

Figure 3 depicts:

- $85 \%$ felt the internship was useful;

- $11 \%$ felt they were not sure on whether internship added value to them;

- $4 \%$ felt the internship was not useful 


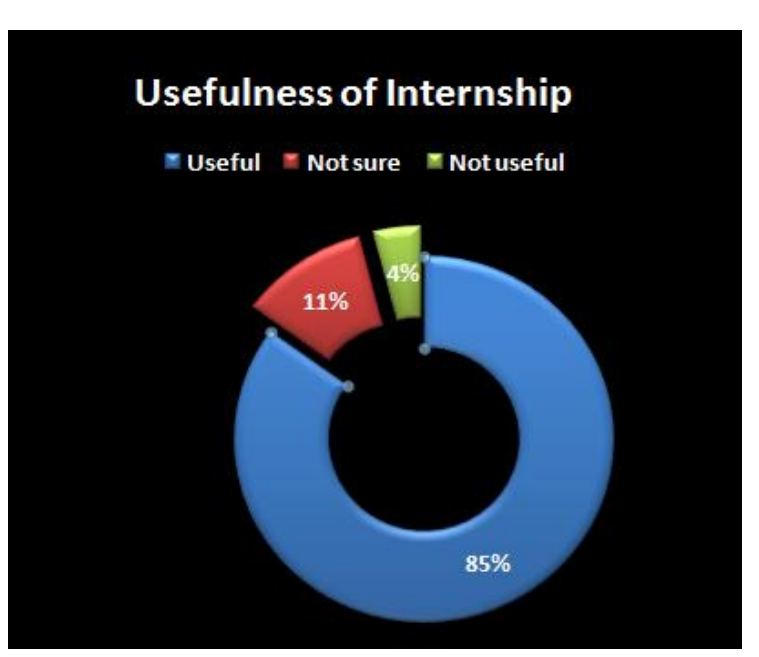

Figure 3. Usefulness of Internship

\section{Did internship contribute towards employability} skills development?

Out of $85 \%$ of the interns who felt the internship to be useful

- $87 \%$ felt that the internship contributed towards developing their employability skills but felt some skills still needed improvement;

- $11 \%$ felt they were not finding internship to have major impact on developing employability skills;

- $2 \%$ felt there was no contribution at all towards employability skills development.

The Figure 4 outlines the same data.

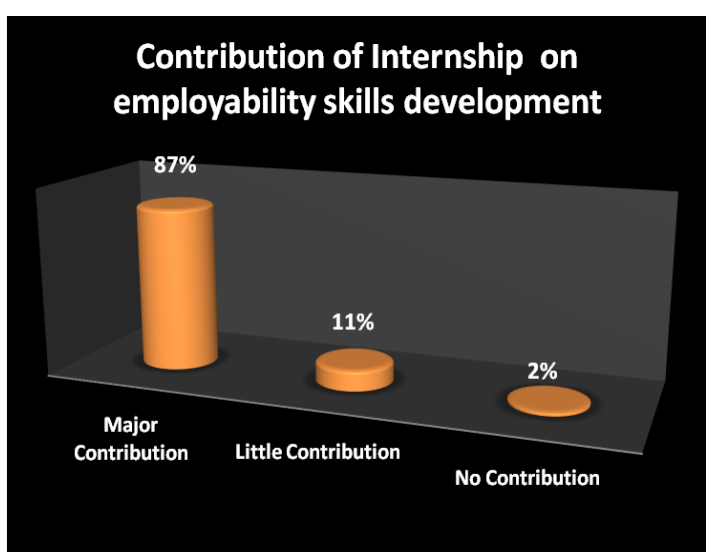

Figure 4. Internship contribution on employability skills development

\section{Helpfulness of Support sessions}

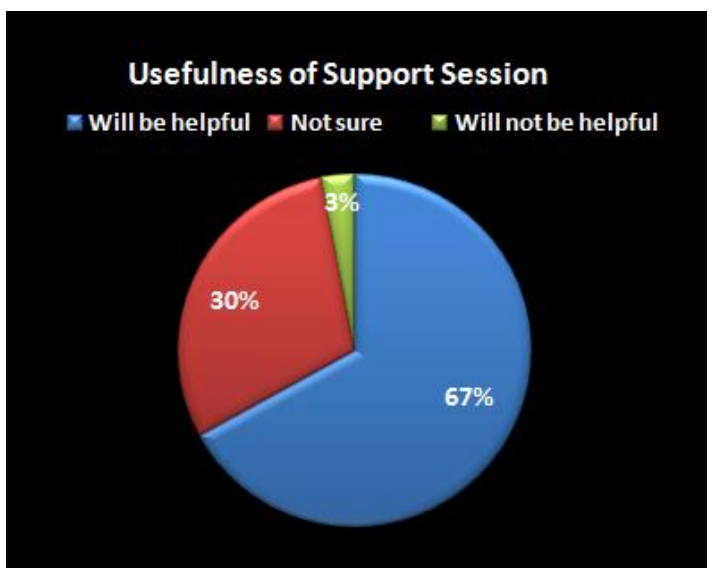

Figure 5. Usefulness of support sessions

Figure 5 outlines the usefulness of the support sessions:

- $67 \%$ of interns felt support sessions will be helpful;

- $30 \%$ of interns felt they were not sure whether support session will be useful;

- $3 \%$ of interns felt it will not be helpful.

\section{Capabilities needing improvement:}

Through the survey it is identified the student should improve on:

- $43 \%$ on communication skills;

- $57 \%$ on time management skills;

- $67 \%$ on stress management skills;

- $56 \%$ on working in team skills ;

- $60 \%$ on problem solving skills.

Figure 6 explains the type of different skills that needs improvement after the first internship.

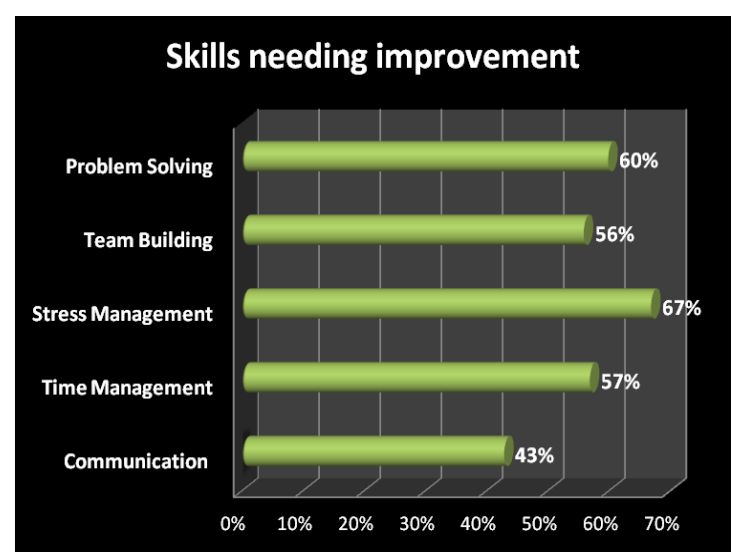

Figure 6. Skills needing improvement 
The above statistical analysis and findings reveal that many interns found their internship to be useful and felt that the support sessions if could be designed around communication, problem solving, time and stress management, team building skills would be greatly useful and helpful. This formed the rationale behind choosing of some key skills from WBSM that need to be taught to current students during their support sessions preparing them for second internship and job. Whilst the proposed curriculum is still under review for approval and implementation as new curriculum for future students, teaching some of the skills as a support sessions will give an insight of the usefulness of the module.

2.3.2.Monitor the module progress. The support sessions on the identified key skills were run 2 hours 3 days in a week for a month prior to students leaving for their second internship and it was not difficult to run these sessions owing to the fact that lot of work had already been done on designing WBSM and because of the cooperation from students due to the attitudinal transformation and maturity gained from their first internship visit. The attendance to these sessions was reported to be good and these students are currently on their second internship.

To monitor the progress formative assessments were designed which could enable the tutors to confirm that their students are improving on the said skills. For the students who still had difficulties additional guidance customized to the individual's need was provided. This helped all the students to improve on their skills to varied levels certainly better from the standpoint where they were in prior to attending the sessions. This is because students are diverse and there are number of factors like back ground, culture, prior learning, grasping capacities which differentiates and disadvantages some students as against their peers in learning despite being given same education or even more training/customized support.

Also, simple motivational competitions were conducted on the said skills to the students enabling them to realize their skills upgradation and giving a sense of accomplishment driving others to aim high towards achieving their aspirations.

The students who attended the sessions felt much more confident and were in appreciation of these support sessions as a mechanism enabling them to perform well during the second internship which is now ongoing. The employers when interviewed were also expressing a similar thought that affirms the usefulness of the WBSM module when could be incorporated as part of new curriculum for future students.
2.3.3.Analysis and feedback. This subsection clearly outlines the usefulness of support sessions in developing relevant skills in students preparing them for second internship and job. The success of support sessions is an informal indicator promising hope in the direction of redesigning curriculum using WBSM as the way forward to create employable graduates.

Out of 506 students who went in for first internship most of them managed to arrange by their own for the second internship however, others were supported by the internship coordinator in finding the internship. Generally, an exit feedback will be taken from the stakeholders at the end of the second internship in order to gauge the usefulness of the internship. However, owing to the reason of module being under review and an interim feedback taken at this stage would be useful to bring in modifications based on valid informative suggestions, an interim feedback was collected from external internship supervisor at work place by asking them to complete a questionnaire on behalf of the interns supervised. This feedback mainly focused on finding out the performance of the interns on their professional, social skills, work ethics and management skills while at work place and hence usefulness of support sessions in developing the required skill set. Some of the skills considered as part of the questionnaire are categorized under the four mentioned categories and are as follows,

- Professional skills:
a. Productivity
b. Communication
c. Technical skills
d. Creativity

- Social skills

a. Initiative

b. Interpersonal

c. Professionalism

d. Team Playing

- Work Ethics

a. Punctuality

b. Reliability

c. Appropriate Attire

d. Work standards

- Management Skills

a. Time Management

b. Stress Management

c. Problem Solving

Out of 506 interns who went for second internship, internship tutors managed to collect the feedback on the performance of 435 interns. However, only 417 of the forms were fully 
completed and hence were used in the following data analysis. The summarized findings are given below,

The following pie chart Figure 7 clearly depicts the performance of the interns under the four mentioned categories of skills. It has been noticed that the majority of interns have acquired the necessary social skills and work ethics need for the work place. However the improvements were needed on the dimension of the professional skills and management skills. Though it needs improvements, still it is not found very alarming. The individual skills analysis revealed where the concentration should really to be focused.

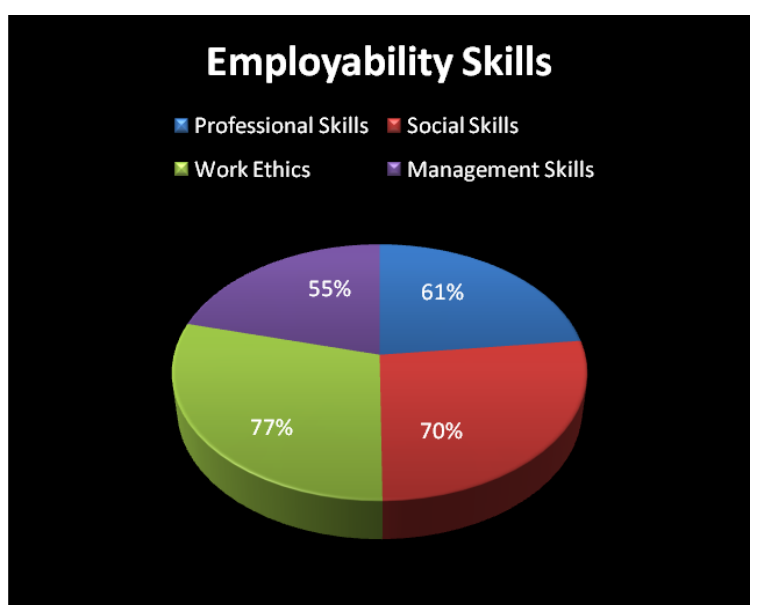

Figure 7. Performance measurement categories

\section{Professional Skills}

Figure 8 portrays the percentage of the different key performance factors associated with the professional skills development,

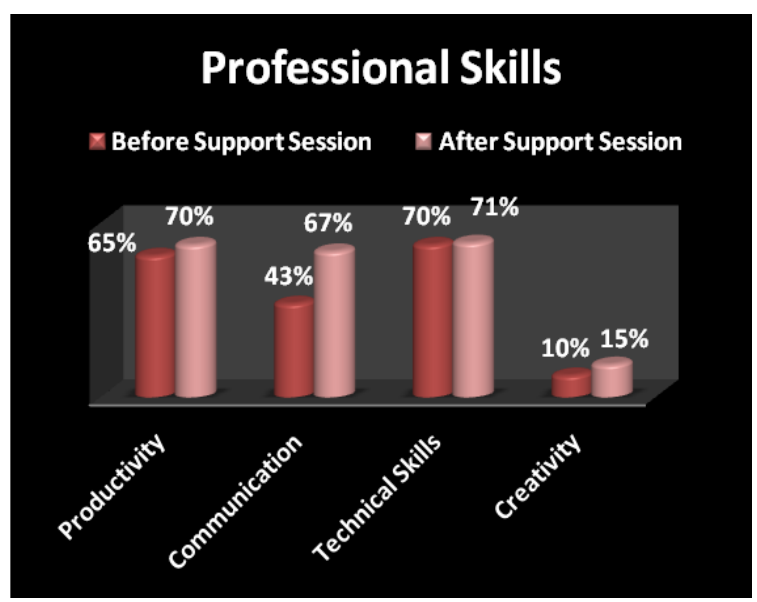

Figure 8. Professional skills performance factors
The improvement found for the communication skills in the above statistical analysis could be attributed to the support session given to students on the above area. However, technical skills being part of current curriculum was not taken into consideration during delivery of support sessions. Productivity could be attributed to technical skill development and knowledge of work and workplace.

The varied technical skills and expertise expected from different organizations may pose a challenge because of the curriculum which needs to be delivered within a limited time frame. This requires initiative from the part of the intern to learn and grasp the requirements of the job. Creativity again was not up to the mark and needs to be developed with experience, interest and initiative and is not a skill to be taught within one month support session. Given more time and resources support sessions on other skills could be considered in near future.

\section{Social Skills}

Figure 9 shows that the social skills have improved compared to the first internship where most of the interns were now easily able to get along with their peers and work together as a team seeking guidance wherever required and demonstrating improved professionalism.

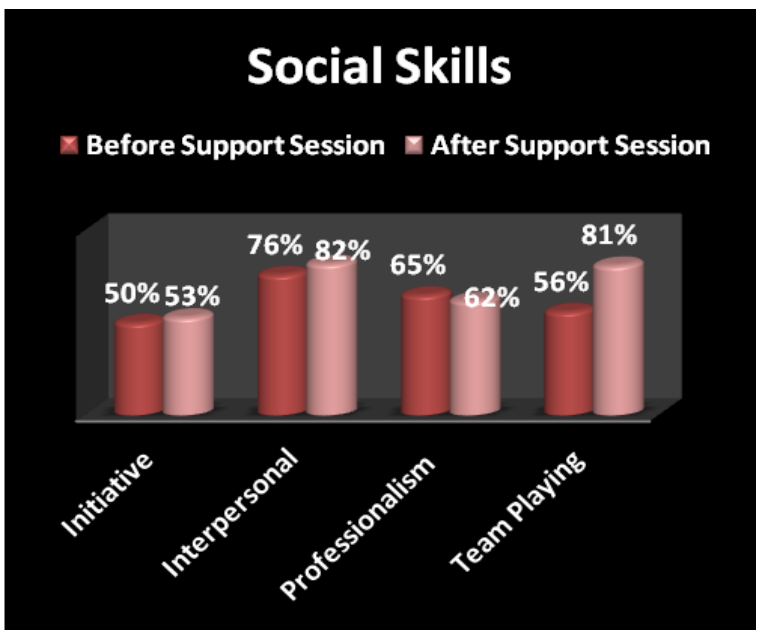

Figure 9. Social skills performance factors

\section{Work ethics}

As shown in Figure 10, the external supervisors were also very happy about the intern's work ethics. Several of them were commending on the punctuality and professional attire of the interns along with a note on improved work standards. 


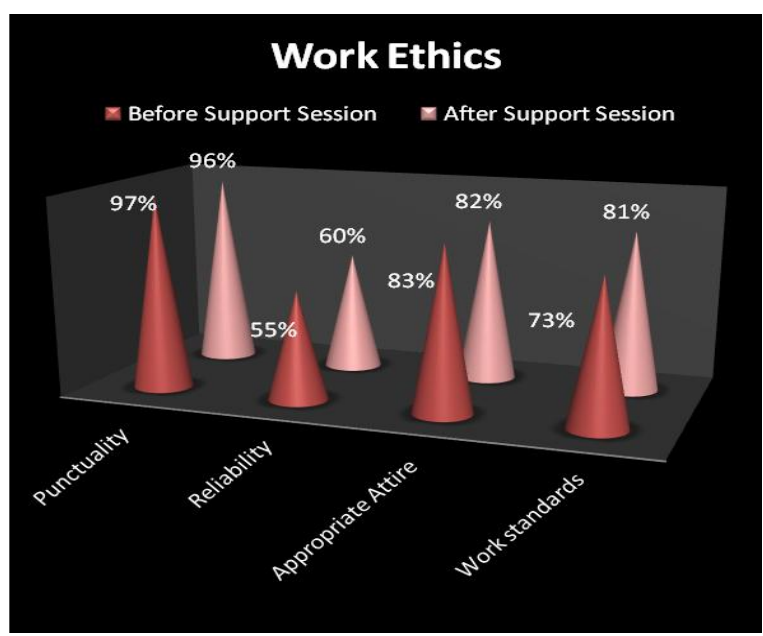

Figure 10. Work ethics performance factors

\section{Management Skills}

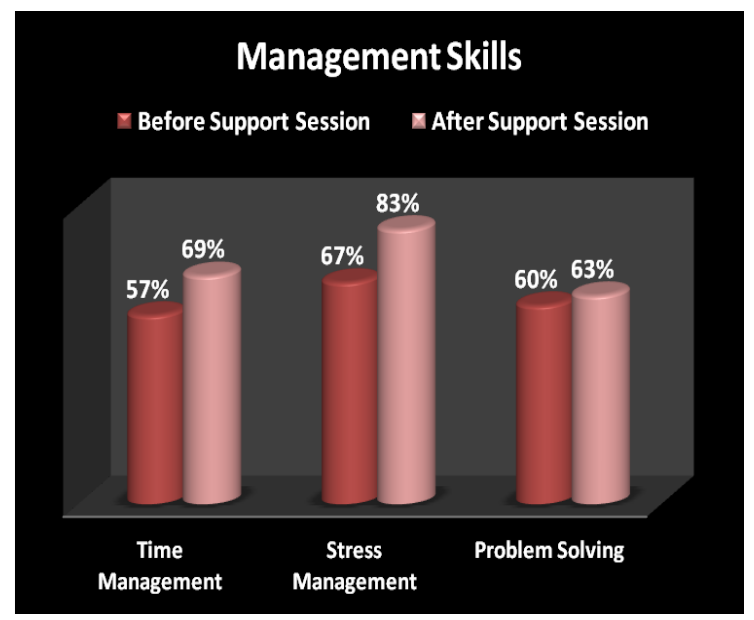

Figure 11. Management skills development after support sessions

Though all of the above listed management skills in the Figure 11 seems to have improved after support sessions yet there is scope for further development on these skills which would be possible with more exposure to projects and situations, work experience, extra support sessions if could be organized.

The above statistical analysis carried out on second internship interns to determine their performance on different employability skills taught to them during the support sessions prior to second internship reveals that the interns are getting prepared with necessary skills to meet the demands of the job market. The Pilot run of the module for fresh tutors and a set of Botho college students prior to their second internship has promised hope in this direction affirming redesigned curriculum to contribute to building employability traits in future graduates .

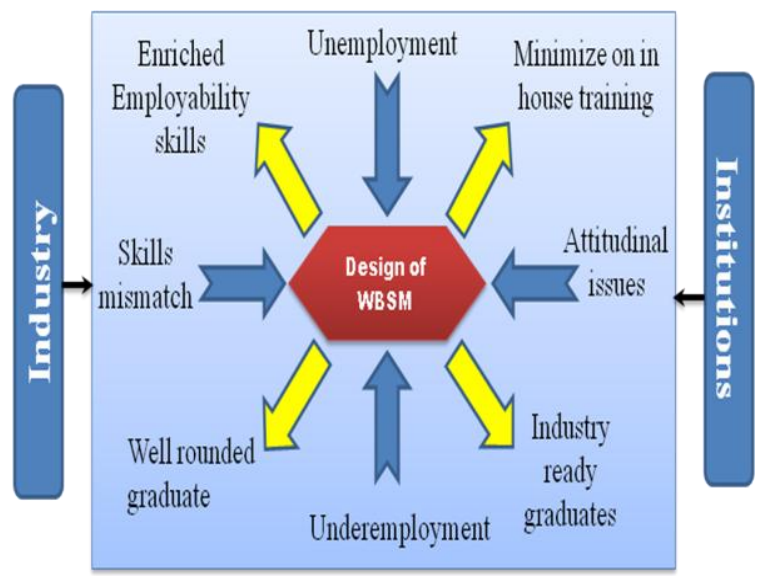

Figure 12. Inputs and outputs of WBMS

The success of this module in turning graduates employable however depends on industry inputs, students ability to grasp work related skills when taught and to make best use of them when at internship and foresees outcome to be a well rounded graduate with good hard and soft skills drawing prospective employers. Figure 12 explains the inputs that was leading to this idea and shows the expected outputs from the WBSM.

\section{Conclusion}

The wide gap that seems to exist between industry and universities needs to be bridged. This would benefit our student community in finding suitable immediate jobs on graduation. Authors believe in incorporating WBSM into the existing curriculum as a promising solution to narrow down the gap.

As a result of running this module the Industries would get trained graduates who can be put to work immediately without spending much time and training resources. Universities on the other hand will have increased student intake due to good employment track records. And most importantly the students of the universities will benefit by this module which prepares them for the competitive job market. The above benefits clearly present a win-win situation for all stakeholders involved.

The successful implementation of this new curriculum upon approval should hopefully create employable graduates with adequate skills to meet the industry demands paving way for a society of knowledgeable and skilled manpower contributing to economic growth and development of the country by large. 


\section{References}

[1] P. Rudzajs, L. Penicina, M. Kirikova, R. Strazdina, (2010), "Towards Narrowing a Conceptual Gap between IT Industry and University", Scientific Journal of Riga Technical University. Computer Sciences, Volume 41 / 2010, 9-16.

[2] http://www.ghanaweb.com/GhanaHomePage/ NewsArchive/artikel.php?ID=183049

(Access date: 10.9.2011)

[3] Franz, Jill M. (2008) A Pedagogical Model of Higher Education/Industry Engagement for Enhancing Employability and Professional Practice. In Proceedings Work Integrated Learning (WIL): Transforming Futures Practice...Pedagogy...

Partnerships, pages pp. 164-169, Manly, Sydney, Australia.

[4] www.tec.org.bw/tec_doc/11_quality_of_local.pdf Quality Of local graduates worries industry captains (Access date: 17.9.2011).

[5] A.Nagappan \& R. Subramanian (2011) "Alumni and Tutor Collaboration for effective teaching/learning in classrooms: Bridging the gap between Industry and Academia", IATED, ICERI 2011 proceedings, ISBN : 978-84-615-3324-4, pg $3477-3484$.

[6] Yorke, M. and Knight, P.T. (2004, reissued 2006) Embedding Employability into the Curriculum. York: The Higher Education Academy. www.heacademy.ac.uk/resources.asp?process=full_r ecord\&section $=$ generic\&id=338 (Access date: 17 Dec 2011).

[7] Lees, D. (2002), Information for Academic Staff on Employabilityll, http://www. palatine.ac.uk/ files/emp/1233.pdf

[8] Weligamage, S. S. and Munasinghe M.A.T.K. (2006). Skills For the Future: Stakeholders“ Satisfaction on Trainee Undergraduates\|, Paper presented at 5th Annual Research Symposium , 8th December 2006, University of Keleniya, Sri Lanka.

[9] Aarthi Nagappan \& Rajesh Subramanian, (2012), "Re-designing curriculum for promoting work based study skills development in Universities: Bridging the Gap between Industry and Academia", CICE 2012 proceedings, ISBN 978-1-908320-07-0,pg 566 $-570$ 